\title{
EGU2020-5568
}

https://doi.org/10.5194/egusphere-egu2020-5568

EGU General Assembly 2020

(c) Author(s) 2021. This work is distributed under

the Creative Commons Attribution 4.0 License.

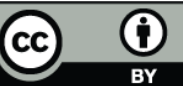

\section{Raman Spectroscopy of Carbonaceous Material record in pseudotachylytes: heating or deformation?}

\author{
Benjamin Moris-Muttoni ${ }^{1}$, Romain Augier ${ }^{1}$, Hugues Raimbourg ${ }^{1}$, and Abdeltif Lahfid $^{2}$ \\ ${ }^{1}$ Institut des Sciences de la Terre d'Orléans (ISTO), Université d'Orléans, CNRS, BRGM, UMR 7327, Orléans, France \\ (benjamin.moris-muttoni@cnrs-orleans.fr) \\ ${ }^{2}$ BRGM, Orléans, France
}

The Raman Spectroscopy of Carbonaceous Materials (RSCM) permits to quantify the degree of crystallinity of carbonaceous materials (CM), which increases upon geological heating. First believed to be a reliable indicator of metamorphic grade (Pasteris and Wopenka, 1991 ; Wada et al., 1996), the quantitative evolution of crystallinity of $C M$ has been proposed as new geothermometers for a wide range of temperature between 200 and $650^{\circ} \mathrm{C}$ (Beyssac et al., 2002 ; Rahl et al., 2005 ; Lahfid et al., 2010 ; Kouketsu et al., 2014).

According to recent studies, RSCM approach has been used to detect evidence of frictional heating during seismic events from pseudotachylites (Ito et al., 2017) or on fault gouges and breccia (Furuichi et al., 2015 ; Kuo et al., 2018). This new application assumes that CM spectra reflect only the thermal record irrespectively of the potential impact of geological strain on CM crystallinity (Tagiri and Tsuboi, 1979 ; Bonijoly et al., 1982 ; Ross et al., 1991 ; Bustin et al., 1995).

The aim of this study is to reconsider this postulate by using RSCM method in order to understand the effects of seismic deformation on the structure of the carbonaceous material. For this purpose, we analyzed three pseuydotachylyte veins from the Shimanto Belt (Southwest Japan), one from a drilling in the Nobeoka Tectonic Line, another from Okitsu area and a last one from the Mugi area, with RSCM method through high-resolution cross-sections perpendicular to the structure. Samples are composed of weakly foliated tectonic melanges troncated by a millimetric shear plane filled by fine black vitreous material accompanied by injection veins. Filling material presents an important grain-size reduction and embayment structures of sandstones clasts, scattered iron sulfides while element maps show flow textures. These microstructure features are described as characteristics of melt-origin pseudotachylytes (Hasegawa et al., 2019) but could also be produced by an intense comminution along with fluids circulation. Area ratio show a large evolution of CM spectra inside the pseudotachylyte compare to the host rock. In addition, intensity ratio (i.e. R1 in Beyssac et al., 2002) drastically increases inside the pseudotachylyte as expected. However, intensity ratio values are higher than expected values at this temperature, from your own calibration on undeformed samples, and highest values are observed on each rim of the pseudotachylyte. This result suggest that structural evolution of CM is not only controlled by temperature, but also by deformation, in a broad sense. More importantly, these parameters 
shows a very sharp evolution in few microns along cross-sections, which is at variance with thermal diffusivity models applicable for others intrusive bodies (Aoya et al., 2010 ; Hilchie and Jamieson, 2014).

These observations of step-wise evolution of CM raman parameters suggest that deformation is the principal influencing factor of the evolution of $\mathrm{CM}$ crystallinity in fault cores. It therefore questions the maximum temperature reached fault zones, possibly much lower than previously estimated. 